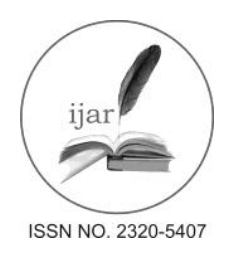

Journal homepage: http://www.journalijar.com

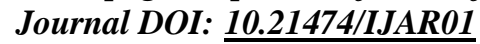

INTERNATIONAL JOURNAL

OF ADVANCED RESEARCH

RESEARCH ARTICLE

\title{
A SURVEY ON REVOLUTION OF BIG DATA PROCESS ANALYTICS.
}

\author{
Dr.I. Lakshmi.
}

Assistant Professor, Department of Computer Science, Stella Maris College, Chennai.

\section{Manuscript Info}

Manuscript History:

Received: 14 April 2016

Final Accepted: 19 May 2016

Published Online: June 2016

Key words:

Big data, data visualization, data analytics, hadoop.

*Corresponding Author

Dr.I. Lakshmi.

\begin{abstract}
This paper is the audit paper which gives the outline of different overviews done by organizations like TCS and IDC Enterprise on Big Data. It has turned out to be enormous news overnight and there are no signs that intrigue is diminishing. In the course of the most recent four years, organizations around the globe have stirred to another bearing: Big Data carries with it Big Responsibility. Enormous Data is in this manner imperative to build efficiency development in the whole world since it is influencing programming concentrated commercial enterprises as well as open spaces like instruction, wellbeing field ,training and managerial areas. Enormous information alludes to voluminous information which ranges in Exabyte's (1018) and past. It is characterized as the measure of information just past innovation's ability to store, oversee and handle productively. The worldview of preparing tremendous datasets has been moved from concentrated engineering to conveyed design. In this paper, we give a broad study of Big information examination research, while highlighting the particular worries in Big information world. We exhibit a scientific categorization in view of the key issues around there, and talk about the diverse techniques to handle these issues. Taking into account this review study numerous midmarket associations report a requirement for instruments running from continuous preparing to prescient examination, information purifying, and information perception.
\end{abstract}

Copy Right,IJAR, 2016, All rights reserved.

\section{Introduction:-}

As the present innovation empowers us to effectively store and question extensive datasets, the emphasis is currently on strategies that make utilization of the complete information set, rather than examining. This has huge ramifications in zones like example acknowledgment, machine learning and characterization, to give some examples. In this manner, there are various necessities for moving past standard information mining systems:

* a hearty exploratory foundation to have the ability to choose a satisfactory technique or configuration

* a new calculation;

* a innovation stage and satisfactory advancement abilities to have the capacity to actualize it;

* a honest to goodness capacity to comprehend not just the information structure (and the ease of use for a given preparing strategy), additionally the business esteem.

Thus, assembling multi-disciplinary groups of "Information researchers" is regularly a key method for picking up an aggressive edge. Like never before, protected innovation and patent portfolios are getting to be vital resources. One of the impediments to far reaching investigation reception is an absence of comprehension on the most proficient method to utilize examination to enhance the business [1] "Huge Data" is a term enveloping the utilization of procedures to catch, prepare, dissect and imagine conceivably extensive datasets in a sensible time span not available to standard IT innovations. By expansion, the stage, devices and programming utilized for this object are 
on the whole called "Huge Data technologies".[12] as of late, Big Data has turned into a noteworthy theme in the field of ICT. It is clear that Big Data implies business opportunities, additionally real research challenges. As per McKinsey and Co[2] Big Data is "the following outskirts for headway, rivalry and productivity"[2]. The impact of Big Data gives not just a gigantic potential for rivalry and development for individual organizations, yet the right utilization of Big Data additionally can build efficiency, progression, and aggressiveness for whole divisions and economies. Huge Data can possibly upset exploration, as well as instruction [3]. A late definite quantitative examination of various methodologies taken by 35 sanction schools in NYC has found that one of the main five strategies connected with quantifiable scholarly viability was the utilization of information to guide direction [4]. There is a solid pattern for huge Web organization of instructive exercises, and this will make an inexorably gigantic measure of definite information about understudies' execution. [10]

It is broadly trusted that the utilization of data innovation can decrease the expense of medicinal services while enhancing its quality [5], by making mind more preventive and customized and constructing it with respect to more broad (home-based) nonstop checking. McKinsey gauges [6] a funds of 300 billion dollars consistently in the only us. Thus there have been powerful cases made for the estimation of Big Data for urban arranging (through combination of high-loyalty land information), wise transportation (through investigation and representation of live and nitty gritty street system information), natural displaying (through sensor organizes pervasively gathering information) [7],financial systemic danger examination (through incorporated examination of a web of agreements to discover conditions between budgetary substances) [8], country security (through investigation of interpersonal organizations and monetary exchanges of conceivable terrorists), PC security (through investigation of logged data and different occasions, known as Security Information and Event Management (SIEM)), etc.

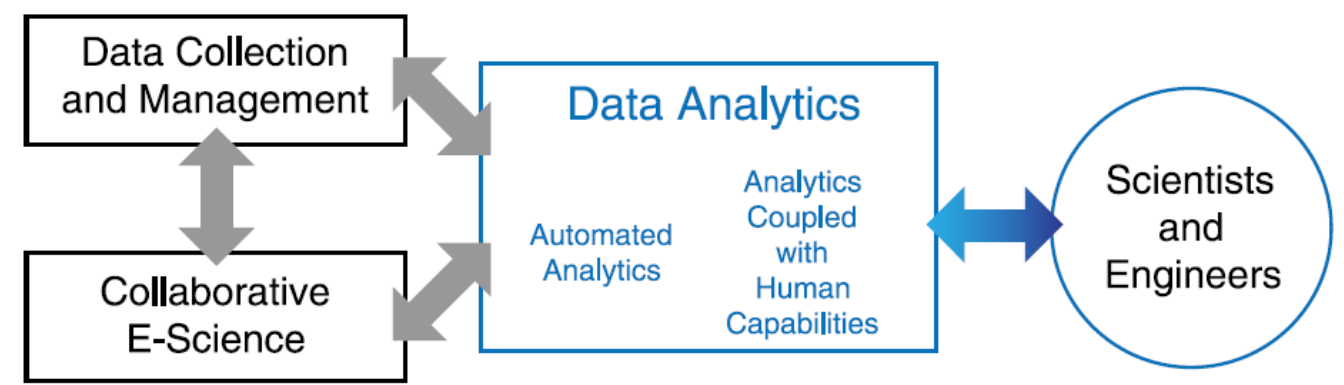

Fig 1:- For regulatory science, one of the most important aspects of big data research is Data Analytics, which is a key for moving from data to human insights.[12]

The goal of this paper is to discuss in detail the current research that addresses these issues. We review the proposed solutions, and study the upcoming research challenges in Big data Analytics.

\section{Big data challenges:-}

The greatest difficulties of enormous information is confronting the four $\mathrm{V}^{\text {ee }} \mathrm{s}$ which is [13]

1. Volume which is the most obvious part of enormous information alluding to the way that the measure of created information has expanded colossally the previous years. The regular extension of web has made an expansion in the worldwide information creation. A reaction to this circumstance has been the virtualization of capacity in server farms, opened up by a noteworthy abatement of the expense of proprietorship through the speculation of the cloud based arrangements. The noSQL database methodology is a reaction to store and inquiry immense volumes of information intensely circulated.

2. Velocity which catches the developing information creation rates. More information are delivered and should be gathered in shorter time spans. The day by day expansion of a huge number of associated gadgets (advanced mobile phones) will increment volume as well as speed. Constant information handling stages are currently considered by worldwide organizations as a prerequisite to get an aggressive edge.

3. Variety is clarified with the duplication of information sources where comes the blast of information arrangements, extending from organized content to free content. The need to gather and investigate nonorganized or semi-organized information conflicts with the conventional social information model and 
question dialects. This reality has been a solid inspiration to make new sorts of information stores ready to bolster adaptable information models.

4. Value is profoundly subjective viewpoint alludes to the way that up to this point, expansive volumes of information where recorded or administrative yet not misused. Huge Data advances are currently seen as empowering influences to make or catch esteem from generally not completely misused information. Basically, the test is to figure out how to change crude information into data that has esteem, either inside, or for making a business out of it.

\section{Research challenges:-}

Everybody is discussing Big Data. The world information is multiplying at regular intervals .There are 7 billion individuals in the world,5.1 Billion of them possess a mobile phone. Every day we send more than 11 billion writings, watch more than 2.8 billion You tube recordings and perform very nearly 5 billion Google hunts and we are not simply expending it we're making it. The information specialists - generate more than 2.5 Quintillion bytes regular from specialized gadgets, buyer exchanges, online conduct and gushing administrations. In 2012 the world's data totalled more than two zeta bytes that is 2 trillion gigabytes .By 2020 we will require 10 times more servers, 50 times more information administration, 75 times more documents to handle it all .If we see most organizations they aren't prepared. $80 \%$ of this new information is unstructured, it is excessively unpredictable and excessively analyzed, making it impossible, making it impossible to be examined by conventional instruments . There are 500k PC researchers yet just $3 \mathrm{k}$ mathematicians. We will miss the mark regarding the ability expected to see enormous information by no less than 100k .To discover opportunities in huge information we require new apparatuses and new ability to mine this data and discover esteem .We require huge information investigation which is more than just innovation .It's another state of mind which will help organizations better comprehend clients, find shrouded opportunities even help our administration better serve subjects and relieve misrepresentation . It will rouse hundred; thousand and even million of new companies.We are toward the start of the enormous information insurgency.

\section{The paper surveys:-}

In the course of the most recent three years, numerous exploration works has experienced in Big Data. Many articles have showed up in the general business press (for instance, Forbes, Fortune, Bloomberg Business Week, The Wall Street Journal, The Economist)[9]. A March 2013 pursuit on Amazon.com surfaces more than 250 books, articles and ebooks on the point. The innovation research group: Gartner, Forrester, IDC are all required into Big Data Study. The 2014 IDG Enterprise Big Data examination was finished with the objective of picking up a superior comprehension of organizationse enormous information activities, speculations and techniques [11]. Key Findings Include [11]:

* Organizations are seeing exponential advancement in the measure of information made do with a normal increment of $76 \%$ inside the following 12 -year and a half.

* Companies are raising their endeavors to determine esteem through enormous information activities with almost half (49\%) of respondents as of now actualizing huge information ventures or during the time spent doing as such later on; in any case, undertaking associations are on top of things in execution arranges contrasted with SMB associations.

* CEOs are fixated around on the estimation of enormous information and are banding together with IT officials who will buy/oversee/execute on the systems.

* Organizations are putting resources into creating or purchasing programming applications, extra separate equipment, and enlisting staff with examination aptitudes in readiness for enormous information activities.

* Organizations are confronting various difficulties with huge information activities and restricted accessibility of gifted representatives to investigate and oversee information beat the rundown.

* In the following 12-year and a half, associations plan to put resources into expertise sets essential for huge information organizations, including information researchers (27\%), information planners (24\%), information examiners $(24 \%)$, information visualizers $(23 \%)$, research investigators $(21 \%)$, and business investigators $(21 \%)$.

* Half of respondents demonstrated there is no reasonable thought pioneer in the huge information arrangement space. 
IDG Enterprise's 2014 Big Data examination was led online among the group of onlookers of six IDG Enterprise brands - CIO, Computerworld, CSO, InfoWorld, IT world and Network World - through web pop-up, discussion posts, and email solicitations. Results depend on 751 respondents. Late in 2012, TCS propelled its own study on Big Data. It focussed on six center issues, which required consideration [9].

* How much are organizations putting resources into Big Data, and what sorts of profits would they say they are accomplishing on their spending?

* What are organizations in 12 commercial ventures doing with Big Data? That is, in which business capacities and particular exercises would they say they are centering their ventures?

* What sort of digitized information are they observing to be most critical ?

* How would they say they are arranging the experts who handle and examine Big Data (e.g., implanted in business capacities, in a focal examination bunch, and so on.), and what are the upsides and drawbacks of those reporting connections?

* What are the greatest difficulties of transforming Big Data into bits of knowledge that empower the organization to settle on obviously better and speedier choices [9]?

* What is the present condition of the innovation, and where is it going?

They're Spending a Lot on Big Data [9]

* The ventures these organizations made in Big Data were sizable. We measure those interests in two routes: by the middle and the normal review respondent:

* Median spending on Big Data was $\$ 10$ million, which was $0.14 \%$ of income (in light of middle income of review respondents: $\$ 6.9$ billion). We trust the middle spending numbers give a more precise picture of spending on Big Data than the mean (or normal) numbers here since the mean was skewed due to various respondents (7\% of the ones we requested spending information) who spent more than $\$ 500$ million on Big Data in 2012.

* The normal review respondent spending on Big Data was $\$ 88$ million in 2012, which was 0.5\% of normal income (of $\$ 19$ billion). Once more, we trust this is a less solid pointer of what organizations are spending on Big Data.

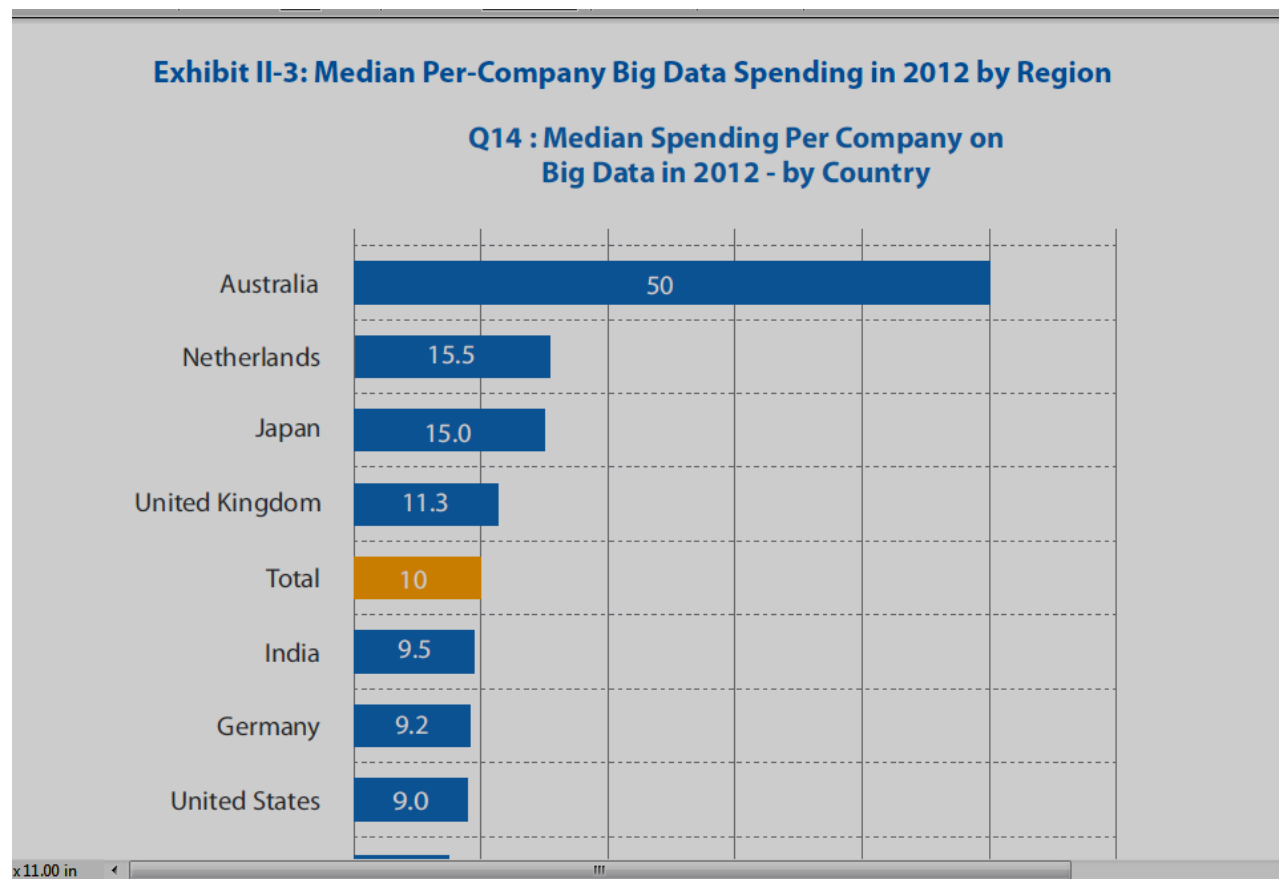

Fig 2:- Median per Company Big data spending in 2012 by region [9] 
By the year 2015, companies across the surveyed regions expect to spend $75 \%$ more on Big Data, with Australia and U.K. companies projecting the highest spending per company. Median spending across all countries is projected to increase by $75 \%$ to $\$ 17.5$ million. (Fig 3.) [9]

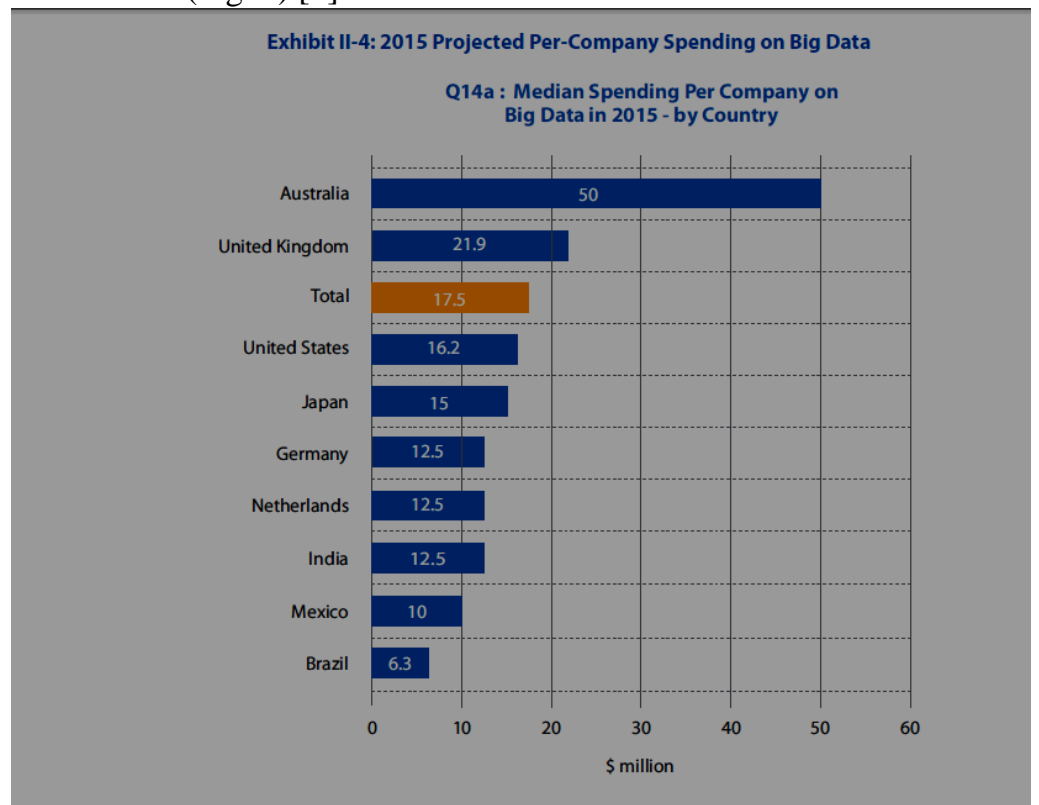

Fig 3:- 2015 Projected Per- company Spending on Big Data[9]

\section{Big Data is Improving Decisions in Most Companies [9]:-}

Slicing and dicing huge volumes and varieties of digital data can keep data scientists busy for days or even weeks. But if the insights they derive do not provide useful guidance - or if business managers don "t utilize that guidance all that spending is futile. To find out, the survey first asked participants whether their initiatives had improved decision making in the business. The answer for the clear majority $-80 \%$-- was indeed yes. The lowest percentage of improvement in decision making was in the U.S. (77\%) while the highest was in Latin America (86\%). (See Fig 4.)[9]

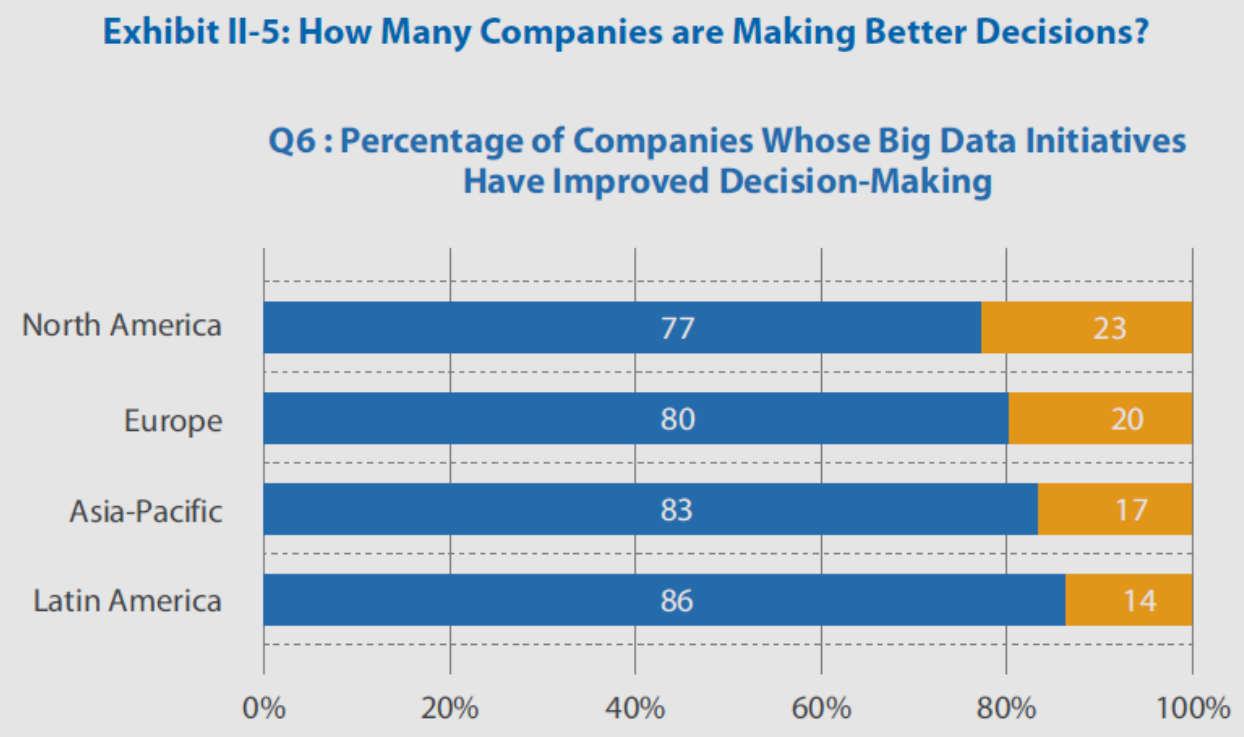

Fig 4:- Percentage of companies whose big data initiatives have improved decision making [9] 
* The company has a Big Data initiative(s) in place, and it has improved decision-making in the business.

* The company has a Big Data initiative(s) in place, and it hasn't yet improved decision-making in the business.

\section{What Kinds of Digital Data are Companies Using[9]?}

One way those Big Data experts such as Tom Davenport distinguish between the eras of „bige and "littlee data is on the type of data companies are using. Big Data is more associated with unstructured and external data

\section{Defining Types and Sources of Digital Data[9]:-}

In our research, we defined data along two dimensions: structured versus unstructured and internal versus external. Given below are the definitions we used. On the dimension of data structure:

* Structured - Data that resides in fixed fields (for example, data in relational databases or in spreadsheets)

* Unstructured - Data that does not reside in fixed fields (for example, free-form text from articles, email messages, untagged audio and video data, etc.)

* Semi-structured - Data that does not reside in fixed fields but uses tags or other markers to capture elements of the data (for example, XML, HTML-tagged text)

On the dimension of data source:

* Internal - from a company's sales, customer service, manufacturing, and employee records; from visits to the company's website, etc.

* External - from sources outside a company such as third-party data providers, public social media sites such as Face book, Twitter and Google+, etc.

A much higher than anticipated percentage of data was not structured - either unstructured or "semi-structured"e (when combined, about half ) [9]. (See Fig 5.)

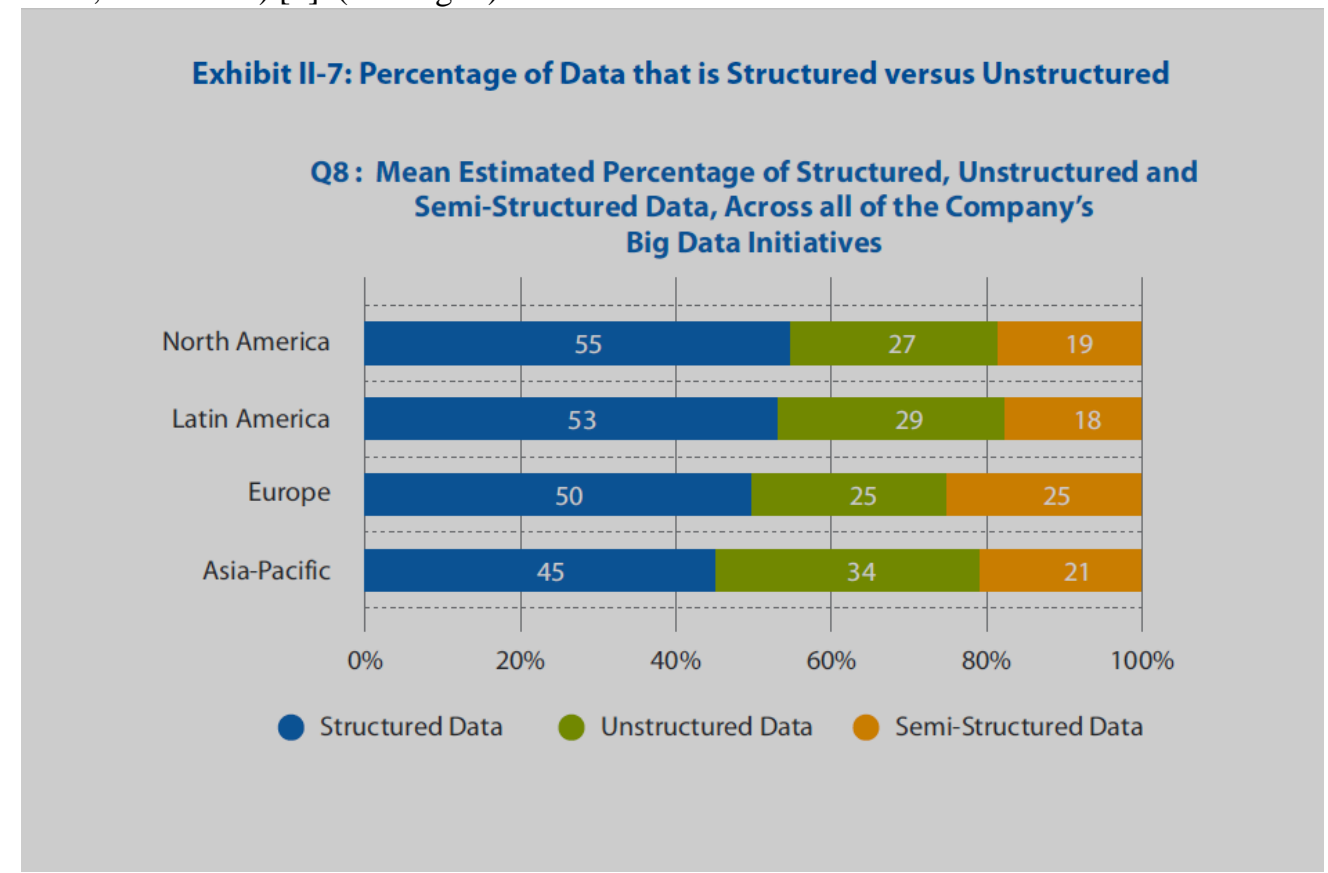

Fig. 5:- Percentage of Data that is structured versus Unstructured [9]

"Studies have been done on electronic records that show, on average, $80 \%-90 \%$ or more of data in records is unstructured data," one health care executive said. " 


\section{Who is Selling Their Big (Digitized) Data [9]?}

In 2012, about one-quarter of the companies we surveyed (27\%) were capitalizing on this opportunity: selling their digital data. U.S. companies profited least from such data, with only $22 \%$ doing so. In contrast, half the Asia-Pacific companies we polled said they sell their digital data. About one-quarter of European and Latin American companies sold their digital data in 2012[9]. (See Fig 6.)

\section{Exhibit II-9: Who's Selling Their Digital Data?}

\section{Q10: Percentage of Companies that Sell their Digital Data}

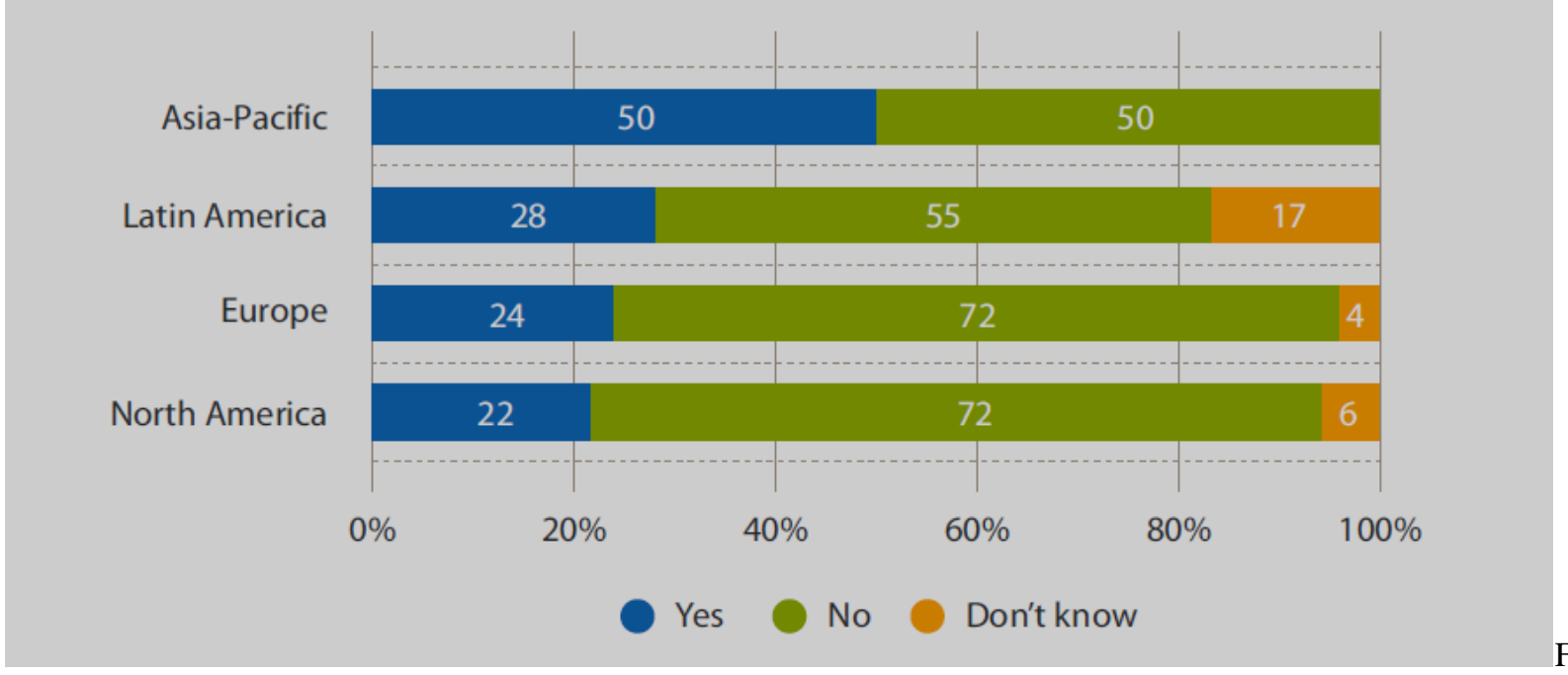

fig 6:- Percentage of companies that sell their digital data[9]

Views of the visionaries [9]:-

To get some insights into what the technology makes possible today and what it may make possible in the near future, TCS interviewed their leading pioneers of Big Data technologies: Joseph Heller stein of the University of California at Berkeley. Here are the highlights of those discussions. "We're in the Early Days of Big Data - Like the Early 1900s' Era Before Washing Machines" Joseph Heller stein, Chancellor's Professor of Computer Science, UC Berkeley, EECS Computer Science Division. Joseph Heller stein likens today's times for Big Data to the early 1900s before the advent of the washing machine. (The first electric washing machines began appearing in the first decade of that century.) Back then, women spent an average 60 hours a week manually washing clothes [9]. Cleansing Big Data is in a similar state, Heller stein believes. He and several colleagues interviewed 35 analysts in companies across industries. They told them they spent $60 \%$ to $80 \%$ of their time on data preparation. "We're getting data from all over the place and it's not prepared for analysis or to be integrated with other data and analysis tools[9]," he says. "The tools available are not designed for analysts." Heller stein sees a big opportunity in bringing data cleansing into the modern-day equivalent of the electric washing machine. He is founder and CEO of a data analysis tools start-up called Trifacta[9]. 


\section{Exhibit VII-7: Where to Begin (and End) with Big Data}

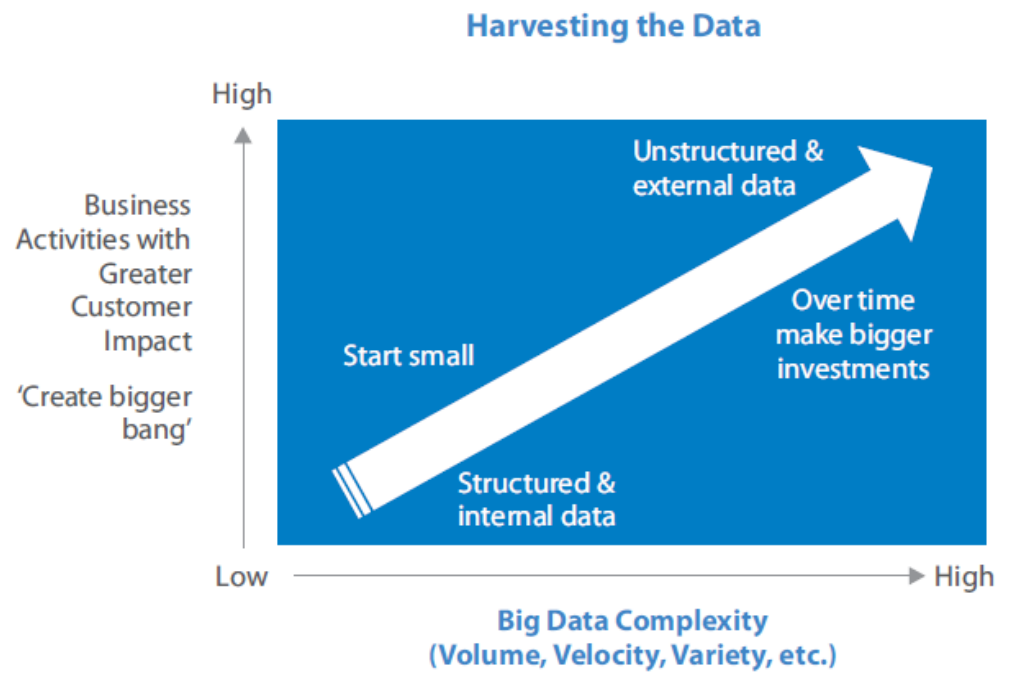

'Create Bigger Competitive Barriers'

Fig 7:- Big data Complexity[9]

\section{Survey Demographics: Getting a 360-Degree View on Big Data[9]:-}

To get a better picture of how companies are using Big Data, we designed the study to collect data from IT, business functions, and analytics managers. Nearly one third were IT managers; 62\% were from eight business functions(marketing, sales, service, production/manufacturing, logistics, research \& development, finance, and human resources). And the remainder (7\%) operated in analytics groups[9]. (See Fig 8.) In all, 88\% either headed one of those functions or reported to the head of it. We also wanted people in these functions who had intimate knowledge of their company's Big Data activities. The majority (58\%) said they played supporting roles in this endeavour, and 23\% played leading roles. The rest (19\%) said they had no role but substantial knowledge about what their company was doing with Big Data.

Exhibit VIII-1: Survey Respondents by Functional Role

Q3: Respondents by Function

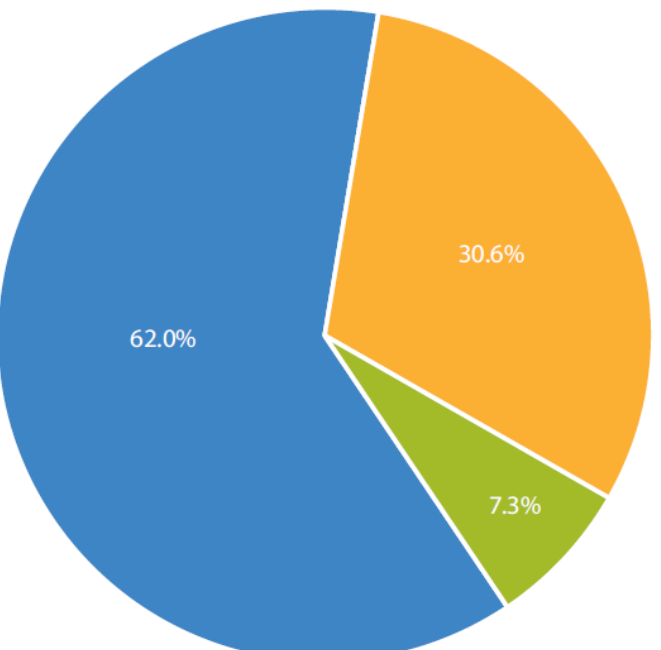

Fig 8:- Survey Respondents by functional Role[9] 


\section{Conclusion and future work:-}

As we have entered in a time of Big Data, there is the potential for making benefits in numerous investigative teaches and ventures through better examination of the substantial volumes of information that is getting to be accessible. Nonetheless, numerous specialized difficulties like information Visualization and execution is to be contemplated in future. This is only the overview paper which demonstrates the interest of huge information and how enormous organizations are taking enthusiasm for it. We should bolster and support major examination towards tending to these specialized difficulties on the off chance that we are to accomplish the guaranteed advantages of Big Data. As Hadoop stretches out into new markets and sees new utilize cases with security and consistence challenges, the advantages of preparing delicate and lawfully ensured information with all Hadoop tasks and HBase must be combined with assurance for private data that points of confinement execution sway.

\section{References:-}

1. LaValle et al: Big Data, Analytics and the Path From Insights to Value, (Dec 2010)

2. McKinsey Global Institute, Big Data: The next frontier for innovation, competition and productivity (June 2011)

3. Advancing Personalized Education. Computing Community Consortium. Spring 2011,jan1.

4. Getting Beneath the Veil of Effective Schools: Evidence from New York City. Will Dobbie, Roland G. Fryer, Jr. NBER Working Paper No. 17632. Issued Dec. 2011.

5. Smart Health Wellbeing. Computing Community Consortium. Spring 2011.

6. Big data: The next frontier for innovation, competition, and productivity. James Manyika, Michael Chui, Brad Brown, Jacques Bughin, Richard Dobbs, Charles Roxburgh, and Angela Hung Byers. McKinsey Global Institute. 15 May 2011.

7. A Sustainable Future. Computing Community Consortium. Summer 2011.

8. Using Data for Systemic Financial Risk Management. Mark Flood, H V Jagadish, Albert Kyle, Frank Olken, and Louiqa Raschid. Proc. Fifth Biennial Conf. Innovative Data Systems Research, Jan. 2011.

9. The Emerging Big returns on big data,TCS-Big-Data-Global-Trend-Study-2013,mar 21,2013

10. Challenges and Opportunities with Big Data, Divyakant Agrawal, Philip Bernstein, Elisa Bertino ,Susan Davidson, Umeshwas Dayal, 1-1-2011

11. IDG ENTERPRISE RESEARCH REPORTS,jan 6,2014 ,http://www.idgenterprise.com/report/big-data-2 [12] Grand Challenge: Applying Regulatory Science and Big Data to Improve Medical Device Innovation, Arthur G. Erdman*, Daniel F. Keefe, Senior Member, IEEE, and Randall Schiestl, IEEE TRANSACTIONS ON BIOMEDICAL ENGINEERING, VOL. 60, NO. 3, MARCH 2013

12. Big Data A new World of Opportunities ,Nessi White Paper , December 2012. 